\title{
MedChemComm
}

Check for updates

Cite this: Med. Chem. Commun., 2018, 9, 583

Received 19th January 2018,

Accepted 16th February 2018

DOI: $10.1039 / \mathrm{c} 8 \mathrm{md} 00033 f$

rsc.li/medchemcomm

\section{Conformationally restricted benzothienoazepine respiratory syncytial virus inhibitors: their synthesis, structural analysis and biological activities $\uparrow$}

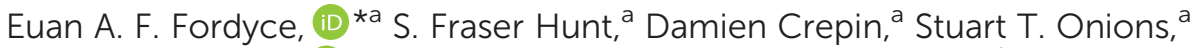 \\ Guillaume F. Parra, (D) ${ }^{\text {a }}$ Chris J. Sleigh, ${ }^{a}$ John King-Underwood, ${ }^{b}$ \\ Harry Finch ${ }^{c}$ and John Murray*c
}

\begin{abstract}
Atropisomeric drug substances are known to have different biological properties. Compounds containing the $\mathrm{N}$-benzoylbenzazepine motif have been shown to exhibit energetically restricted rotation around the $\operatorname{Ar}(\mathrm{CO}) \mathrm{N}$ axis. Herein we report, for the first time, the synthesis, physical characterisation and anti-viral profiles of a series of C-4 and C-5 methylated thieno-benzazepines. NMR analysis reveals that incorporation of a single additional substituent at either of these loci influences the conformational dynamics of the azepine ring system. In the case of the C-5 alkyl analogues, the influence of the new stereocentre is so pronounced that its absolute configuration determines which unique atropisomer is obtained following the generation of the benzazepine nucleus. Screening of the alkylated derivatives for their anti-respiratory syncytial virus (RSV) activity indicates that the desired viral pathogenicity is strongly associated with the conformation adopted by the modified tricyclic scaffolds. This is particularly evident in the case of the C-5 homologues in which one atropisomer was found to be potently active and the other essentially inert. These results provide compelling evidence that we have determined the bioactive conformation shared by RSV inhibitors that employ the thienobenazapine nucleus as their core molecular architecture. Furthermore, the understanding obtained from these studies may make it possible to design improved agents against RSV infection in the future.
\end{abstract}

The importance of molecular stereoisomerism in biological systems and in drug design is well understood. ${ }^{1}$ However a form of chirality which may be present in therapeutic agents, and is often less well recognised, derives from atropisomerism. ${ }^{2}$ Unlike compounds that contain classical, carbon-centered stereogenic centres, which are only able to interconvert through the breaking and re-making of chemical bonds, atropisomers result from energetically restricted rotation about a single bond or axis. This is a time dependent process influenced by factors such as the degree of steric hindrance, stereoelectronics, temperature and the nature of the environment, such as the presence of a solvent. By convention

\footnotetext{
${ }^{a}$ Sygnature Discovery Ltd., BioCity, Nottingham, NG1 1GF, UK. E-mail: e.fordyce@sygnaturediscovery.com; Tel: +44 (0)1159415401

${ }^{b}$ CompChem Resource, Old Cottage Hospital, Homend, Ledbury, Herefordshire, HR8 1ED, UK

${ }^{c}$ Pulmocide Ltd., 52 Princes Gate, Exhibition Road, South Kensington, London, SW72PG, UK. E-mail: john@pulmocide.com; Tel: +44 (0)2037639484

$\dagger$ Electronic supplementary information (ESI) available. See DOI: 10.1039/ c8md00033f
}

atropisomers are recognised as physically separable species, with a half-life of at least 1000 seconds. ${ }^{3}$ Natural product examples include mastigophorene A $1,{ }^{4}$ known to aid nerve growth, and $(M)$-murrastifoline-F $2,{ }^{5}$ an alkaloid isolated from the roots of the curry leaf plant Murraya koenigii (Fig. 1). Of particular relevance to the present study are atropisomers that arise in compounds incorporating asymmetric medium-sized rings, such as telenzepine $3 .^{6}$ In these cases the distinct stereoisomers result not from restricted, single bond rotation but, rather from a 'ring-flip' that interconverts mirror image conformations.

As with other forms of stereoisomerism, atropisomers may exhibit significantly different biological activities, including their pharmacokinetic profiles and toxicities. ${ }^{2 b}$ The selective $\mathbf{M}_{1}$ muscarinic antagonist telenzepine 3, used to treat peptic ulcers, exists as atropisomers that were found to have a halflife $\left(t_{1 / 2}\right)$ for racemisation of 1000 years at $20{ }^{\circ} \mathrm{C}$. Their separation and screening revealed the $(+)$-isomer to be some 500fold more active than the (-)-isomer towards muscarinic receptors of the rat cerebral cortex. ${ }^{6}$

Atropisomers are also reported to be present in tolvaptan 4 (Fig. 2), a selective, competitive vasopressin receptor 2 


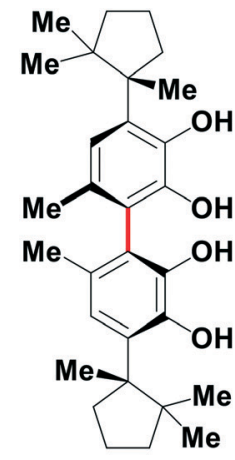

1

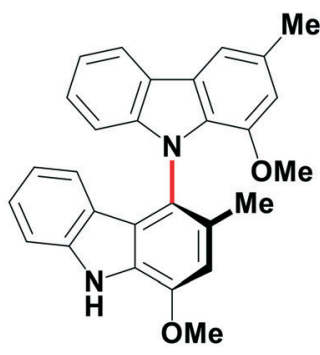

2

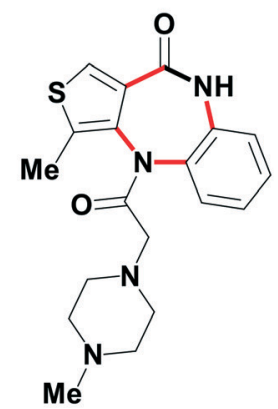

3

Fig. 1 Biologically active compounds that exist as atropisomers.<smiles>Cc1ccccc1C(=O)Nc1ccc(C(=O)N2CCCC(O)c3cc(Cl)ccc32)c(C)c1</smiles><smiles>Cc1cccc2c1N(C(=O)c1ccccc1)CCC(=O)N2C</smiles><smiles>Cc1ccccc1C(=O)Nc1ccc(C(=O)N2CCC(=O)N(C)c3cccc(C)c32)cc1</smiles>

Fig. 2 Structures of vasopressin receptor ligands: tolvaptan 4 ; N-benzoyl-1,5-benzodiazepine derivatives 5 and 6.

antagonist, approved for treatment of autosomal-dominant polycystic kidney disease (ADPKD) ${ }^{7,8}$ Natsugari et al. have reported that the incorporation of a methyl group at C-6 in the closely related 1,5-benzodiazepine 5 also resulted in the formation of conformational isomers. ${ }^{9}$ These atropisomers were separated by chiral HPLC and their absolute configurations determined by X-ray crystallography. The atropisomers of the related analogue 6 exhibited a 9-13 fold difference in affinities towards the human vasopressin $V_{\text {Ia }}$ and $V_{2}$ receptors. The aS isomer was found to be the eutomer at both targets $\left(K_{\mathrm{i}}\right.$ values of 70 and $640 \mathrm{nM}$ for $V_{\mathrm{Ia}}$ and $\left.V_{2}\right)$ and the $\mathrm{a} R$ isomer the distomer $\left(K_{\mathrm{i}}\right.$ values of 620 and $4700 \mathrm{nM}$ respec- tively). These results demonstrate that the conformation adopted by the scaffold region of the 1,5-benzodiazepine nucleus is an important determinant of their activities. Related studies have been undertaken on the corresponding $N$-benzoyl-1,5-benzothiazepines ${ }^{10}$ and $N$-benzoyl-5-hydroxybenzazepines. ${ }^{11}$

We have previously reported a number of potent RSV polymerase inhibitors based on a thienobenzazepine tricyclic scaffold (8a/b; Fig. 3). ${ }^{12,13}$

NMR analysis of representative examples revealed the presence of restricted rotation around the $\operatorname{Ar}-\mathrm{N}(\mathrm{C}=\mathrm{O})$ axis (Fig. 4), although the interconversion of the axial isomers at<smiles>[R7]C=Cc1nc2c(F)cccc2[nH]1</smiles>

Fig. 3 Structures of benzothienoazepine based RSV polymerase inhibitors. 
<smiles>Cc1ccc(C(=O)N2CCc3cc(C)sc3-c3ccccc32)cc1</smiles>

Fig. 4 Conformations benzothienoazepines.

room temperature was too rapid to permit their isolation. However, the incorporation of a substituent into the azepine ring (at $\mathrm{C} 4$ and $\mathrm{C5}$ ) of such substrates, not previously reported, was expected to exert a profound effect on the conformational energetics of the resulting seven-membered ring.

Herein we report the synthesis and characterisation of both C-4 and C-5 methylated thienobenzazepines and describe the effect of the resulting axial chirality on their RSV inhibitory potencies.

Synthesis of the 4-methylazepine derivatives commenced with reduction of the methyl ester 9 (Scheme 1), followed by regioselective bromination of the thiophene ring and protection of the pendant primary alcohol, to give compound $\mathbf{1 0 .}$ This intermediate was lithiated, trapped with ethyl chloroformate, ${ }^{14}$ and the resulting ethyl bromothiophene-2carboxylate coupled with 2 -( $N$-Boc-amino)phenylboronic acid pinacol ester. Removal of the silyl protecting group revealed the alcohol 11, the precursor for the key cyclisation reaction.
The annulation proceeded via a one pot Mitsunobu/Boc deprotection sequence ${ }^{15}$ which afforded benzazepine derivative 12a together with dihydroquinoline derivative $12 \mathbf{b}^{16}$ These two compounds were readily separated by chromatography and the desired azepine 12a acylated with 4-nitrobenzoyl chloride and the ester hydrolysed to yield the thiophene carboxylic acid 13. This intermediate was then converted into the desired 4-methylazepine carboxamide 14 using conditions similar to those already reported elsewhere. ${ }^{12}$

The 5-methylazepine analogue was accessed starting from the 3-thiophene ethanol (15, Scheme 2). Oxidation of the primary alcohol with Dess-Martin periodinane and then Grignard addition with methylmagnesium iodide yielded the corresponding secondary alcohol in good yield. Directed bromination and protection of the pendant alcohol as the $t$-butyldimethylsilyl ether was followed by lithiation and trapping with ethyl chloroformate. ${ }^{14}$ The resulting bromothiophene 16 was coupled with 2-( $N$-Boc-amino)phenylboronic acid pinacol ester and the product treated with TBAF to afford the cyclisation precursor 17. As described above for the 4-methyl analogue, the annulation step was achieved by a Mitsunobu/Boc deprotection sequence ${ }^{15}$ which afforded the desired C-5 methylated, thienobenzazepine 18 in $40 \%$ yield. ${ }^{17}$ Following acylation with 4-nitrobenzoyl chloride and hydrolysis of the ethyl ester the corresponding thiophene carboxylic acid 19 was converted into the regioisomeric analogue 20 using conditions previously disclosed. ${ }^{12}$

The single enantiomers of compound 20, of known absolute configuration at $\mathrm{C}-5$, were prepared by modifying the route described above, employing either $(R)$ - or $(S)$-2-

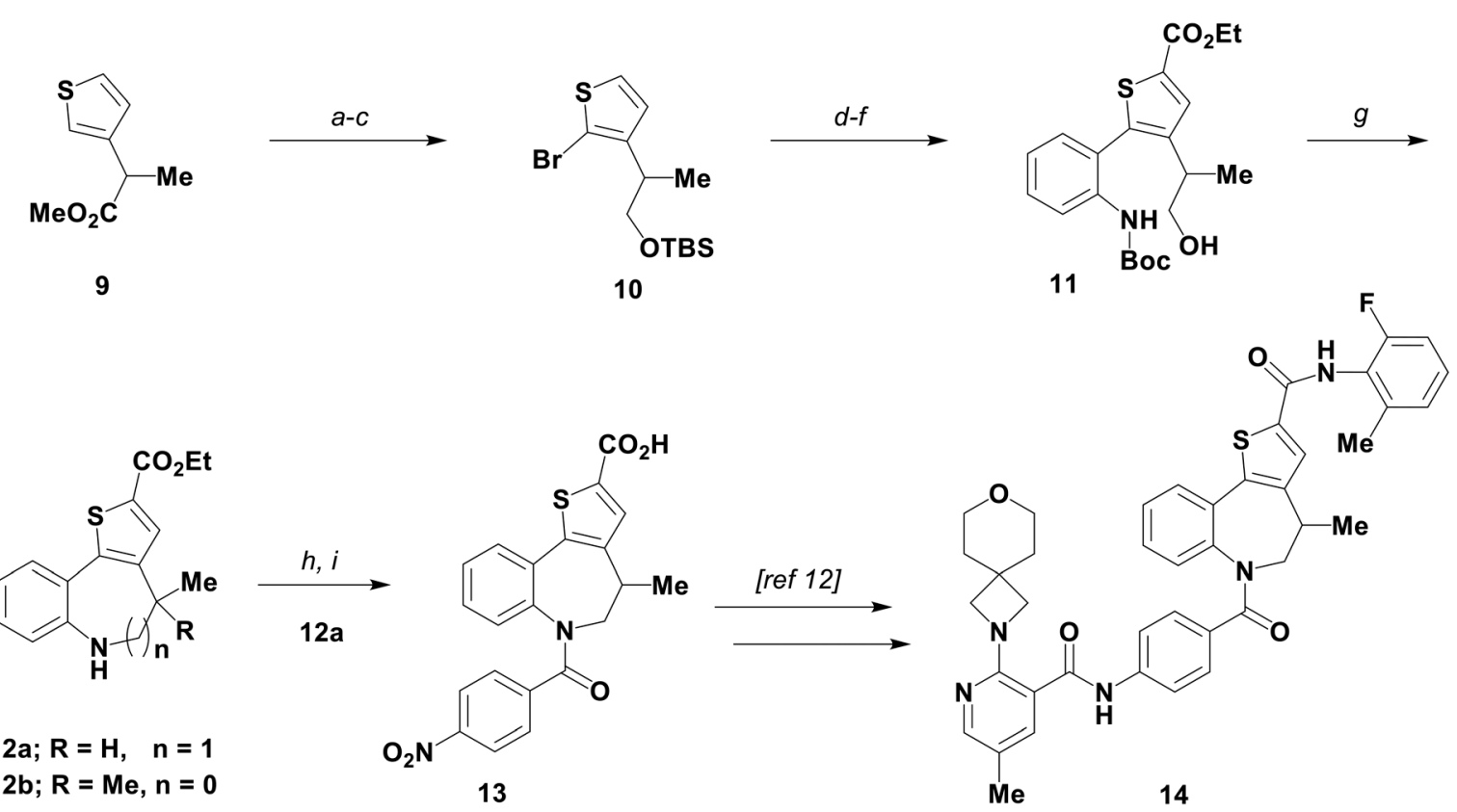

Scheme 1 Synthetic route for the preparation of 4-methylazepine derivative $14^{a}$. ${ }^{a}$ Reagents and conditions: (a) $\mathrm{LiAlH}_{4}, \mathrm{THF}, 0{ }^{\circ} \mathrm{C}$ to $\mathrm{RT}, 88 \%$; (b) NBS, DCM, AcOH. RT, 63\%; (c) TBSCl, ImH, DMF, RT, 70\%; (d) $\mathrm{ClCO}_{2} \mathrm{Et}, \mathrm{LDA}, \mathrm{THF},-78$ to $-40{ }^{\circ} \mathrm{C}, 39 \%$; (e) $\mathrm{ArB}(\mathrm{pin}), \mathrm{Pd}\left(\mathrm{PPh}_{3}\right)_{4}, \mathrm{Na} 2 \mathrm{CO}{ }_{3}, 1,4-$ dioxane : $\mathrm{H}_{2} \mathrm{O}$ (1:1), $95{ }^{\circ} \mathrm{C}, 76 \%$; (f) TBAF, THF, RT, 90\%; (g) PPh, DIAD, PhMe, $0{ }^{\circ} \mathrm{C}$ to reflux then TFA, RT, $54 \%+19 \%$ of $12 \mathrm{~b}$; (h) ArCOCl, py, RT to $50{ }^{\circ} \mathrm{C}, 90 \%$; (i) $\mathrm{LiOH}, \mathrm{THF}: \mathrm{MeOH}: \mathrm{H}_{2} \mathrm{O}(1: 1: 1), \mathrm{RT}, 97 \%$. 


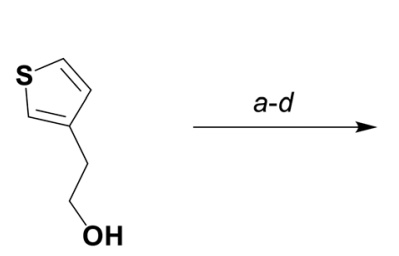

15<smiles>CCOC(=O)c1cc2c(s1)-c1ccccc1NC(C)C2</smiles>

18<smiles>CCOC(=O)c1cc(CC(C)[O+]S(C)(=O)=O)c(Br)s1</smiles>

16
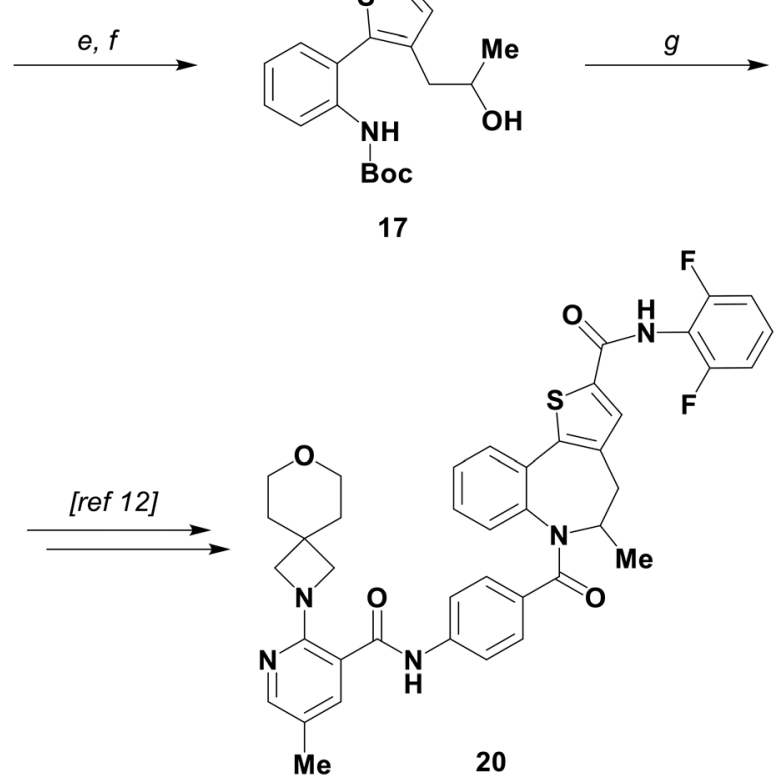

Scheme 2 Synthetic route for the preparation of 5-methylazepine derivative $20^{a}$. ${ }^{a}$ Reagents and conditions: (a) DMP, DCM, RT then MeMgl, Et $2 \mathrm{O}$, $0{ }^{\circ} \mathrm{C}$ to RT, 69\%; (b) NBS, DCM, AcOH. RT, 78\%; (c) TBSCl, ImH, DMF, RT, 90\%; (d) $\mathrm{ClCO}_{2} \mathrm{Et}_{1} \mathrm{LDA}, \mathrm{THF},-78{ }^{\circ} \mathrm{C}, 39 \%$; (e) $\mathrm{ArB}(\mathrm{pin}), \mathrm{Pd}(\mathrm{PPh})_{4}, \mathrm{Na}_{2} \mathrm{CO}_{3}$, 1,4-dioxane : $\mathrm{H}_{2} \mathrm{O}(1: 1), 95{ }^{\circ} \mathrm{C}, 83 \%$; (f) TBAF, THF, $0{ }^{\circ} \mathrm{C}$ to $\mathrm{RT}, 87 \%$; (g) $\mathrm{PPh}_{3}, \mathrm{DIAD}, \mathrm{PhMe}, 0{ }^{\circ} \mathrm{C}$ to reflux then TFA, RT, $40 \%$; (h) ArCOCl, py, RT to $50{ }^{\circ} \mathrm{C}, 92 \%$; (i) $\mathrm{LiOH}, \mathrm{THF}: \mathrm{MeOH}: \mathrm{H}_{2} \mathrm{O}(1: 1: 1), \mathrm{RT}, 92 \%$.

methyloxirane as the source of the secondary stereocentre. For the $(5 R)$-derivative, 3-bromothiophene 21 was treated with $n$-BuLi and the resulting lithiated thiophene added to $(S)$-2methyloxirane (Scheme 3). Since the enantiopurity of the resulting secondary alcohol could not be determined at this stage, the assessment of optical purity was undertaken later; after construction of the thienobenzazepine core was completed. The subsequent Mitsunobu reaction, performed on the cyclisation precursor $(S)-\mathbf{1 7}$ was anticipated to proceed with clean inversion, leading to $(5 R)-23$, after acylation with 4-nitrobenzoyl chloride and obtained at an enantiomeric excess $>99 \%$. The corresponding (5S)-stereoisomer was accessed in a similar manner. In this instance, 3-bromothiophene was transmetallated using $i$-PrMgCl-LiCl, to give the corresponding turbo Grignard reagent, ${ }^{18}$ for the subsequent epoxide opening with $(R)$-2-methyloxirane. The resulting alcohol was then transformed, as described above, into the $N$-benzoyl thienobenzazepine $(5 S)$-23 which was also determined to have formed in $>99 \%$ ee. These intermediates were converted into the single C-5 enantiomers of compound 20 by the synthetic methods described previously.

Structural analysis of the azepine ring systems was undertaken by examining the ${ }^{1} \mathrm{H}$ NMR spectra acquired on the less complex carboxylic acid precursors 7 (Fig. 3), 13 and 19 (Schemes 1 and 2). It has previously been reported that compounds of a chemotype similar to the unsubstituted azepine 7 can exist as four possible stereoisomers, ${ }^{9}$ arising from a combination of cis/trans isomers of the amidic bond ${ }^{19}$ and the presence of atropisomers, resulting from the restricted interconversion of alternative conformations of the azepine ring (Fig. 4). The ${ }^{1} \mathrm{H}$ NMR spectrum of compound 7 (Fig. 1, in ESI $\dagger$ ) reveals the $\mathrm{C}-4$ and $\mathrm{C}-5$ methylene protons to be diastereotopic, supporting the existence of restricted rotation in this axis of the tricyclic core. The difference in the chemical shifts of the two protons on C-5 are particularly marked, appearing as multiplets at $4.9-4.8$ and $3.4-3.3 \mathrm{ppm}^{20}$ This is

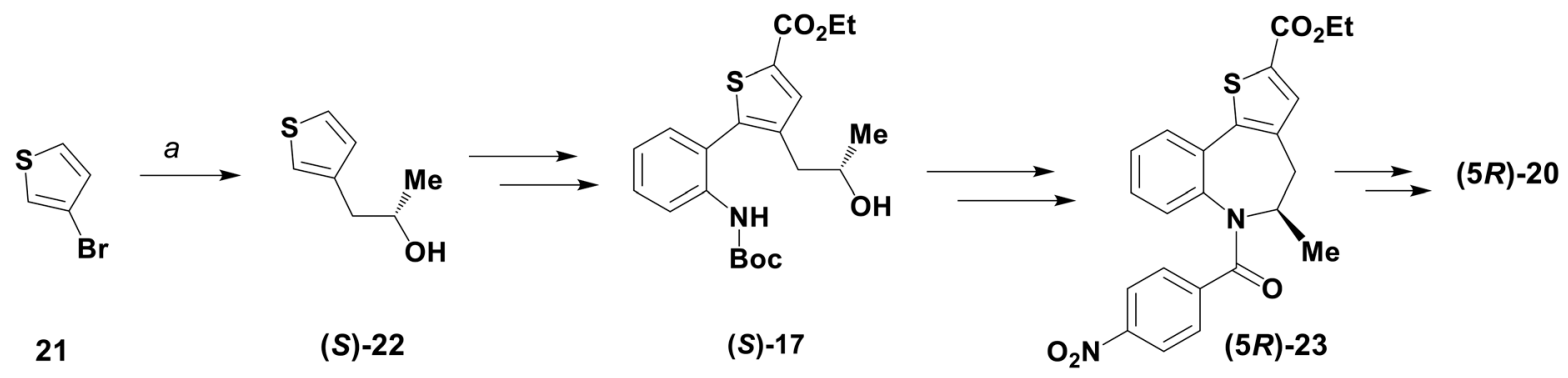

Scheme 3 Enantiospecific synthesis of $(R)-20^{a}$. ${ }^{a}$ Reagents and conditions: (a) (S)-2-methyloxirane, $n B u L i, \mathrm{BF}_{3} . \mathrm{Et}_{2} \mathrm{O}, \mathrm{THF}-78$ to $0{ }^{\circ} \mathrm{C}, 74 \%$. 
consistent with the conclusion that compound 7 exists as $(\mathrm{a} S)$ and $(\mathrm{a} R)$-axial conformers that interconvert only slowly on the NMR timescale.

This conclusion was confirmed by the generation of a new (racemic) stereocentre at $\mathrm{C}-4$ in compound 13, which results in the formation of azepine ring conformers that are diastereomeric in nature; a result that is clearly evident from the doubling observed for the alkylene proton signals (Fig. 2, in ESI $\dagger$ ). Integration of the resonances for the individual ring conformers indicates that they are no longer energetically equivalent and are present in a 5:3 ratio. Based on the coupling constants observed for the protons of the azepine ring and analysis of the NOEs observed it is believed that the major isomer present is the anti diastereomer. ${ }^{21}$ It was possible, by chiral HPLC, to resolve the mixture into separate $(4 S)$ and $(4 R)$ enantiomers, each of which exhibited the same $5: 3$ ratio of signals attributed to the diastereotopic conformations of the azepine nucleus. The results obtained from these experiments reveal that C-4 alkylation influences the conformational preference of the resulting seven membered ring, although interconversion is still too rapid to permit isolation of individual atropisomers. The existence of this dynamic equilibrium at ambient temperature was evident from 1D NOE experiments conducted on compound 13. Selective irradiation of the C-5 proton resonating at $3.00 \mathrm{ppm}, \mathrm{H} 5 \mathrm{a}$, resulted in an NOE interaction with its geminal proton partner, $\mathrm{H} 5 \mathrm{~b}$, at $4.81 \mathrm{ppm}$; as was expected from their through space proximity (Fig. 5). However, transfer of magnetization (exchange) was also observed to occur to the $\mathrm{H}_{5} \mathrm{a}^{\prime}$ signal at $4.76 \mathrm{ppm}$, showing that the H5a proton experiences two distinct environments during the time course of the NOE experiment. The significant difference in chemical shifts $(\Delta \delta 1.76$ ppm) measured for the H5a proton, probably arises from the deshielding influence exerted by the adjacent carbonyl group, depending upon the conformation adopted by the azepine ring system.

In contrast, the ${ }^{1} \mathrm{H}$ NMR spectrum of the 5-methyl analogue, compound 19, reveals the presence of only one diastereomer (Fig. 3 in ESI $\dagger$ ). Furthermore the corresponding spectra obtained from the discrete C-5 stereoisomers of compound
19 were shown to be identical, confirming that, of the four possible isomers, only two are present and they are enantiomeric. Based on their chemical shifts and coupling constants and from 1D NOE experiments (Fig. 6) it is believed that (5R)19 exists solely as the $(\mathrm{a} R)$ atropisomer, whilst the $(5 S)$ epimer is uniquely the corresponding $(\mathrm{a} S)$ atropisomeric derivative.

These results reveal the profound influence of a substituent at C-5 to determine the energetically accessible conformation of the resulting azepine nucleus. In the case of the methylated homologues the presence of the additional alkyl group at this locus is sufficient to 'freeze out' one of the atropisomers by setting the absolute stereochemical configuration at $\mathrm{C}-5$.

Unfortunately all attempts to obtain a crystalline sample of compound 20, suitable for X-ray diffraction analysis were unsuccessful.

Having prepared and characterised the structures of the desired precursors 7, 13, and 19, these intermediates were elaborated, as described above, into the anti-RSV agents 8a, 14 and 20 for use as molecular probes in SAR studies. The in vitro anti-viral potencies of the final compounds were assayed in a standard RSV phenotypic cell screen (Table 1). Racemic compounds (rac)-14 and (rac)-20 demonstrated comparable anti-RSV activity to the parent unsubstituted thienobenzazepine, compound 8a, against both $\mathrm{A} 2$ and B-WST viral strains. The interpretation of this data is that the presence of the additional alkyl group does not prevent one of the stereoisomers of the racemic C-4 and C-5 substituted analogues from attaining the bioactive conformation, thereby exerting a similar activity to the parent compound 8a.

However a large difference in bioactivity emerged on screening the single enantiomers $(4 R)-14$ and (4S)-14 (Table 1, entries 4 and 5). ${ }^{22}$ In this instance the $(4 R)$ enantiomer proved to be comparable to the corresponding racemate. In contrast the $(4 S)$ isomer was 20 fold weaker towards the A2 strain (40\% inhibition at $0.01 \mu \mathrm{M}$ ) and 100 times less potent at inhibiting the CPE induced by the B-WST virus. The diminution in antiRSV activity observed for $(4 S)-14$ is consistent with a disfavourable perturbation of the conformation of the thienobenzazepine ring which must be attained to exert the

B

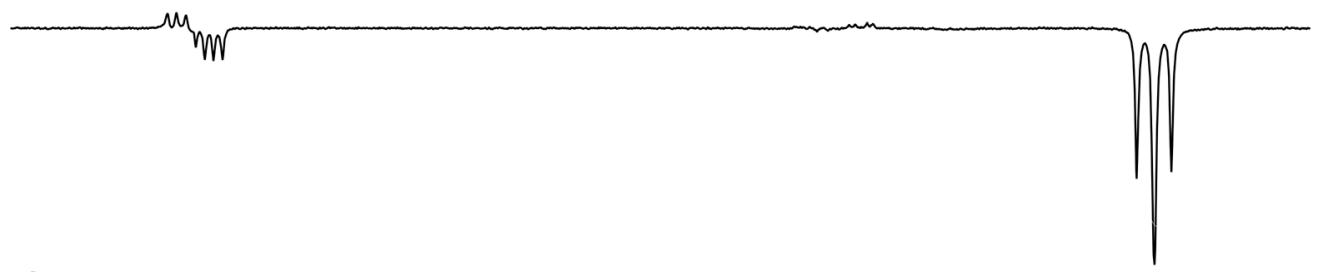

A

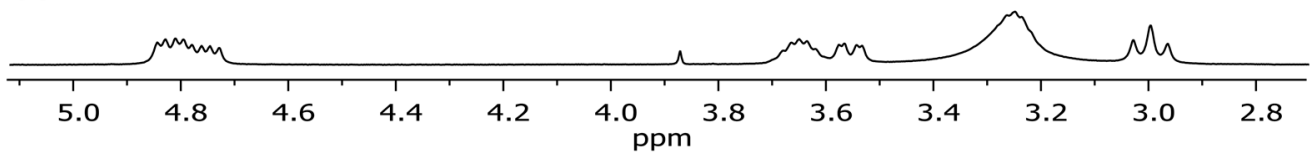

Fig. $5{ }^{1} \mathrm{H}$ NMR spectrum of compound 13 (A) and 1D NOE experiment by selective irradiation of signal H5a (B). 


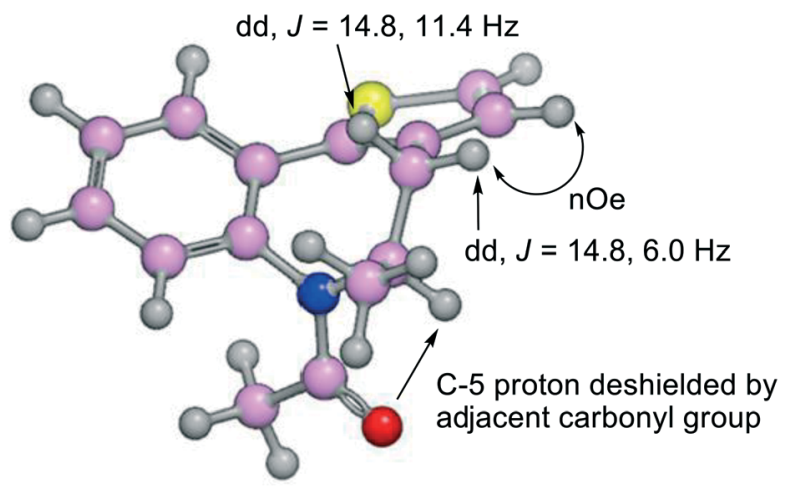

Fig. 6 Chemical shifts and coupling constants for the key protons in the azepine ring of 19 .

desired drug action. A similarly striking result, providing further evidence for this explanation of the SAR, was obtained on screening the single enantiomers of the C-5 substituted homologue: compound 20. The $(5 R)$-isomer was shown to be the eutomer, exhibiting strong activity against both $\mathrm{A} 2$ and $\mathrm{B}-\mathrm{WST}$ viral strains, having $\mathrm{IC}_{50}$ values of 0.29 and $14 \mathrm{nM}$ respectively. By comparison the $(5 S)$ isomer was found to be completely inactive in the concentration range screened (Table 1, entries 6 and 7). ${ }^{23}$

Table 1 Anti-RSV activity and mammalian cytotoxicity for compounds $8 \mathrm{a}, 14$ and 20

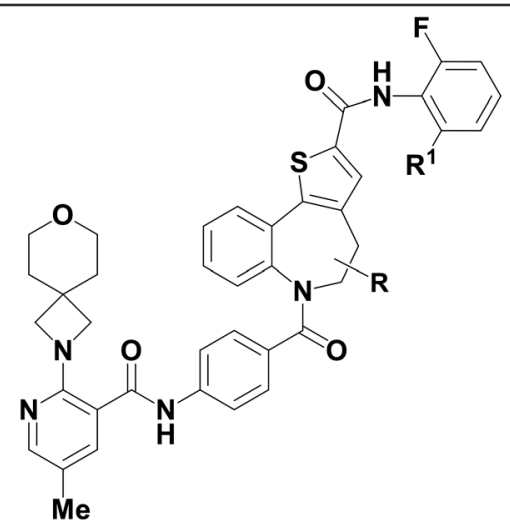

\begin{tabular}{llllll}
\hline & & & & \multicolumn{2}{c}{$\mathrm{IC}_{50}$ values $^{a}(\mathrm{nM})$} \\
\cline { 5 - 6 } Entry & Compound & $\mathrm{R}$ & $\mathrm{R}^{1}$ & $\mathrm{A2}^{b}$ & $\mathrm{~B}-W S T^{c}$ \\
\hline 1 & $\mathbf{8 a}$ & $\mathrm{H}$ & $\mathrm{Me}$ & 0.32 & 7.2 \\
2 & $($ rac $)-\mathbf{1 4}^{d}$ & $4-\mathrm{Me}$ & $\mathrm{Me}$ & 1.1 & 17 \\
3 & $($ rac $)-20$ & $5-\mathrm{Me}$ & $\mathrm{F}$ & 0.45 & 13 \\
4 & $(4 R)-\mathbf{1 4}^{d, e}$ & $4-\mathrm{Me}$ & $\mathrm{Me}$ & 0.51 & 15 \\
5 & $(4 S)-\mathbf{1 4} 4^{d, e}$ & $4-\mathrm{Me}$ & $\mathrm{Me}$ & $>14^{f}$ & $>1370$ \\
6 & $(5 R)-\mathbf{2 0}$ & $5-\mathrm{Me}$ & $\mathrm{F}$ & 0.18 & 9.2 \\
7 & $(5 S)-\mathbf{2 0}$ & $5-\mathrm{Me}$ & $\mathrm{F}$ & $>14^{g}$ & $>1363^{h}$
\end{tabular}

${ }^{a} \mathrm{IC}_{50}$ : drug concentration that reduces by $50 \%$ the cytopathic effect (CPE) of RSV infected HEp-2 cells (ATCC® CCL-23 ${ }^{\mathrm{TM}}$ ); data were averaged from $\geq 2$ experiments. ${ }^{b}$ NCPV, Public Health England (Wiltshire, UK); lot number 0709161v. ${ }^{c}$ ATCC (Manassas, VA, USA); lot number VR-1580. ${ }^{d}$ Present as a 5:3 mixture of atropisomeric diastereomers. ${ }^{e}$ Compound arbitrarily assigned this absolute stereochemical configuration. ${ }^{f} 40 \%$ inhibition at $0.014 \mu \mathrm{M} .{ }^{g}$ No inhibition observed up to $0.014 \mu \mathrm{M} .{ }^{h}$ No inhibition observed up to $1.4 \mu \mathrm{M}$.
In summary we have synthesised a number of C-4 and C-5 methylated thienobenzazapines and demonstrated through NMR analysis that incorporation of these substituents influences the conformations that are energetically accessible to the central seven-membered ring. In particular, the structural elucidation carried out on the progenitors (5- $R$ ) and (5-S) 19 reveals that the presence of the C-5 methyl group exerts such a profound effect that the benzazepine core adopts a unique geometry (atropisomer) that is determined by the absolute stereochemistry of the additional substituent. Screening of the alkylated derivatives for RSV activity indicates that viral pathogenicity is associated with a unique conformation of the tricyclic scaffold of our compounds. Taken together these data are compelling evidence that we have determined the biologically active conformation of the tricyclic core of the anti-RSV compounds presented herein (as represented in Fig. 6). The understanding obtained from the present study has the potential to guide the design of future small molecule RSV inhibitors. Furthermore the benzazepine core is a privileged structure present in a number of marketed pharmaceutical products and the pharmaceutically relevant consequences of locking the conformations of these compounds is as yet unexplored.

\section{Conflicts of interest}

The authors declare no competing interest.

\section{Acknowledgements}

The authors would like to thank Kaz Ito and Heather Allen for the provision of the biological screening data for compounds 8a, 14 and 20.

\section{References}

1 W. H. Brooks, W. C. Guida and K. G. Daniel, Curr. Top. Med. Chem., 2011, 11, 760-770.

2 (a) J. Clayden, W. J. Moran, P. J. Edwards and S. R. LaPlante, Angew. Chem., Int. Ed., 2009, 48, 6398-6401; (b) S. R. LaPlante, L. D. Fader, K. R. Fandrick, D. R. Fandrick, O. Hucke, R. Kemper, S. P. F. Miller and P. J. Edwards, J. Med. Chem., 2011, 54, 7005-7022; (c) P. W. Glunz, Bioorg. Med. Chem. Lett., 2018, 28, 53-60.

3 M. Oki, Top. Stereochem., 1983, 14, 1-76.

4 Y. Fukuyama and Y. Asakawa, J. Chem. Soc., Perkin Trans. 1, 1991, 0, 2737-2741.

5 (a) C. Ito, Y. Thoyama, M. Omura, I. Kajiura and H. Furukawa, Chem. Pharm. Bull., 1993, 41, 2096-2100; (b) G. Bringmann, S. Tasler, H. Endress, J. Kraus, K. Messer, M. Wohlfarth and W. Lobin, J. Am. Chem. Soc., 2001, 123, 2703-2711.

6 P. Eveleigh, E. C. Hulme, C. Schudt and N. J. Birdsall, Mol. Pharmacol., 1989, 35, 477-483.

7 K. Kondo, H. Ogawa, H. Yamashita, H. Miyamoto, M. Tanaka, K. Nakaya, K. Kitano, Y. Yamamura, S. Nakamura, T. Onogawa, T. Mori and M. Tominaga, Bioorg. Med. Chem., 1999, 7, 1743-1754. 
8 Tolvaptan was approved as a treatment for ADPKD in Japan in 2014 and then subsequently in Canada, Europe and Korea in 2015.

9 H. Tabata, J. Nakagomi, D. Morizono, T. Oshitari, H. Takahashi and H. Natsugari, Angew. Chem., Int. Ed., 2011, 50, 3075-3079.

10 T. Yoneda, H. Tabata, T. Tasaka, T. Oshitari, H. Takahashi and H. Natsugari, J. Med. Chem., 2015, 58, 3268-3273.

11 H. Tabata, T. Yoneda, T. Oshitari, H. Takahashi and H. Natsugari, J. Med. Chem., 2017, 60, 4503-4509.

12 For benzamide derivatives see: S. F. Hunt, S. T. Onions, V. Sherbukhin, E. A. F. Fordyce, P. J. Murray, D. W. Brookes, K. Ito and P. Strong, WO2016/055791A1, 2016; S. F. Hunt, S. T. Onions, V. Sherbukhin, E. A. F. Fordyce, P. J. Murray, M. S. Coates, D. W. Brookes, K. Ito and P. Strong, WO2016/ 055792A1, 2016; M. Coates, D. Brookes, Y.-I. Kim, H. Allen, E. A. F. Fordyce, E. A. Meals, T. Colley, C. Lise-Ciana, G. F. Parra, V. Sherbukhin, J. A. Stockwell, J. C. Thomas, S. F. Hunt, L. Anderson-Dring, S. T. Onions, L. Cass, P. J. Murray, K. Ito, P. Strong, J. P. Devincenzo and G. Rapeport, Antimicrob. Agents Chemother., 2017, 61, e00737.

13 For benzimidazole derivatives see: E. A. F. Fordyce, S. F. Hunt, S. T. Onions, V. Sherbukhin, M. S. Coates, D. W. Brookes, K. Ito, P. Strong and J. King-Underwood, WO2016/ 097761A1, 2016; E. A. F. Fordyce, D. W. Brookes, C. LiseCiana, M. S. Coates, S. F. Hunt, K. Ito, J. King-Underwood, S. T. Onions, G. F. Parra, G. Rapeport, V. Sherbukhin, J. A. Stockwell, P. Strong, J. C. Thomas and J. Murray, Bioorg. Med. Chem. Lett., 2017, 27, 2201-2206.

14 It is well known in the literature that $\alpha$-halothiophenes in strong basic media undergo rearrangement reactions. For examples of this base-catalysed halogen dance see: H. Fröhlich and W. Kalt, J. Org. Chem., 1990, 55, 2993-2995 and references therein. We believe that the modest yield obtained for this transformation in part reflects the fact that alternative reaction pathways are available.
15 For similar transformations see: T. Ohtani, Y. Kawano, K. Kitano, J. Matsubara, M. Komatsu, M. Uchida, F. Tabusa and Y. Nagao, Heterocycles, 2005, 66, 481-502; H. Xiong, M. Foulk, L. Aschenbrenner, J. Fan, C.-L. Tiong-Yip, K. D. Johnson, D. Moustakas, P. R. Fleming, D. G. Brown, M. Zhang, D. Ferguson, D. Wu and Q. Yu, Bioorg. Med. Chem. Lett., 2013, 23, 6789-6793.

16 Compound 12b presumably forms via elimination of triphenylphospine oxide from the intermediate alkyloxytriphenylphosphonium species and then acid mediated intramolecular hydroamination. For examples of such hydroaminations, see: G. Hilt, W. Hess and F. Schmidt, Eur. J. Org. Chem., 2005, 2526-2533.

17 The major impurity present in the mixture $(29 \%$ isolated yield) was the corresponding propenyl thiophene 24, present as a 5:1 mixture of cis:trans isomers, which presumably form via elimination of triphenylphosphine oxide from the intermediate alkyloxytriphenylphosphonium species.

18 R. L.-Y. Bao, R. Zhao and L. Shi, Chem. Commun., 2015, 51, 6884-6900.

19 The terms cis and trans describe the relative arrangements of the two benzene rings.

20 Assignment of protons based on HSQC analysis.

21 This terminology was used by Natsugai et al. (see ref. 11) to describe the relative arrangement of a ring substituent and an $N$-benzoyl group in a series of benzazepines. Applying this nomenclature to our system the syn diastereomer is that in which the $\mathrm{C} 4$ methyl and $\mathrm{N}$-benzoyl groups are disposed on the same face of the ring and, conversely, on opposite faces for the anti diastereomer.

22 Compound arbitrarily assigned this absolute stereochemical configuration.

23 For RSV A2 the concentration range screened was $10^{-6}$ to $10^{-2} \mu \mathrm{g} \mathrm{mL} \mathrm{m}^{-1}$ and for RSV B-WST is was $10^{-4}$ to $10^{-1} \mu \mathrm{g}$ $\mathrm{mL}^{-1}$. 